\title{
Umidade do solo e doses de potássio na cultura da soja ${ }^{1}$
}

\author{
Soil moisture and potassium doses on soybean culture
}

\author{
Milson Evaldo Serafim²*, Fábio Benedito Ono ${ }^{3}$, Walmes Marques Zeviani ${ }^{4}$, José Oscar Novelino e Joil Vilhalva Silva $^{6}$
}

\begin{abstract}
Resumo - Os solos tropicais, normalmente pobres em potássio (K), quando cultivados com soja (Glycine max L.) demandam adubação potássica para obtenção de produtividades satisfatórias. Objetivou-se com este trabalho avaliar o efeito de doses de $\mathrm{K}$ e níveis de umidade do solo nos componentes de produção da soja. O experimento foi realizado em casa de vegetação e os tratamentos foram dispostos em um delineamento em blocos casualizados em esquema fatorial ( 5 x 3), com cinco repetições. Um vaso com $5 \mathrm{dm}^{3}$ de solo com duas plantas compôs a parcela experimental. O primeiro fator correspondeu às doses de $\mathrm{K}\left(0 ; 30 ; 60 ; 120\right.$ e $\left.180 \mathrm{mg} \mathrm{dm}^{-3}\right)$ e o segundo fator as faixas de umidade do solo (35 a 40; 47,5 a 52,5; e 60 a $65 \%$ do volume total de poros). Foram avaliados: rendimento de grãos, peso de cem grãos, número total de grãos por vaso, teor de K no grão, número de vagens viáveis. Houve resposta da soja à adubação potássica, com aumento do rendimento de grãos, massa de cem grãos, teor de K no grão e número de vagens viáveis. O total de grãos por vaso atingiu valor máximo na combinação dos limites superiores de cada fator de estudo. O K reduziu os efeitos do défice hídrico na cultura da soja.
\end{abstract}

Palavras-chave - Glycine max. Adubação potássica. Solo-umidade.

\begin{abstract}
The tropical soils, usually poor in potassium (K), demand potassium fertilization when cultivated with soybean (Glycine $\max \mathrm{L}$.) to obtain satisfactory yields. The aim of this study was to evaluate the effects of $\mathrm{K}$ doses and soil humidity levels on soybean agronomic characteristics. The experiment was carried out in a greenhouse, in pots with two plants, containing $5 \mathrm{dm}^{3}$ of soil. The experimental design was completely randomized block with treatments in a $5 \times 3$ factorial arrangement. The $\mathrm{K}$ doses were $0 ; 30 ; 60,120$ and $180 \mathrm{mg} \mathrm{dm}^{-3}$, and the soil humidity ranged from 35 to $40 ; 47.5$ to 52.5 ; and 60 to $65 \%$ of the total porosity. The characteristics appraised were: grain yield, weight of a hundred grains, total number of grains per pot, $\mathrm{K}$ level in the grain, number of viable pods. There was soybean response to the potassium fertilization, with increase of the grain yield, mass of a hundred grains, $\mathrm{K}$ level in the grain and number of viable pods. The grain total per pot reached maximum value in combination of the upper limits of each study factor. The $\mathrm{K}$ reduced the water deficit effects on the soybean.
\end{abstract}

Key words - Glycine max. Potassium. Soil-humidity.

\footnotetext{
*Autor para correspondência

Recebido para publicação em 22/10/2010; aprovado em 03/11/2011

Pesquisa realizada com recursos do Laboratório de solos da Faculdade de Ciências Agrárias/Universidade Federal da Grande Dourados - FCA/UFGD ${ }^{2}$ Instituto Federal de Educação Ciência e Tecnologia de Mato Grosso, Campus Cáceres, Cáceres-MT, Brasil, milson.serafim@cas.ifmt.edu.br ${ }^{3}$ Programa de Pós-Graduação em Ciência do Solo/Universidade Federal de Lavras, Lavras-MG, Brasil, onofabiob@gmail.com ${ }^{4}$ Departamento de Estatística/Universidade Federal do Paraná, Curitiba-PR, Brasil, walmes@ufpr.br

${ }^{5}$ Faculdade de Ciências Agrárias/Universidade Federal da Grande Dourados, Dourados-MS, Brasil, josenovelino@ufgd.edu.br

${ }^{6}$ Faculdade de Ciências Agrárias/Universidade Federal da Grande Dourados, Dourados-MS, Brasil, joilap@ @otmail.com
} 


\section{Introdução}

Os solos dos Cerrados brasileiro, geralmente, são deficientes em potássio (K) por serem altamente intemperizados (MELO et al., 2000; SILVA et al., 2008), o que faz com que as reservas deste nutriente, nesses solos, não suportem cultivos sucessivos devido às grandes quantidades extraídas pela soja (FOLONI; ROSOLEM, 2008). Deste modo, a sua restituição no solo deve ser feita mediante a adubação (LOPES, 2005).

O K é normalmente o mineral mais abundante no tecido vegetal (OLIVEIRA et al., 2001). Entre as várias funções do $\mathrm{K}$ na planta, a regulação da turgidez dos tecidos, abertura e fechamento dos estômatos e controle da transpiração são fundamentais para aumentar a eficiência de uso da água pelo vegetal. Plantas bem supridas de $\mathrm{K}$ são mais eficientes no uso que as deficientes, sendo que a quantidade de água para produzir uma unidade de massa seca, dentro de limites, é tanto menor quanto maior o suprimento de K (NELSON, 2005).

O funcionamento adequado dos estômatos é essencial para a fotossíntese, transporte de água e nutrientes, além do sistema de regulação térmica da planta. Se a quantidade de $\mathrm{K}$ for inadequada, os estômatos tornam-se lentos aumentando as perdas de água, que por sua vez acentua o efeito do défice hídrico. $\mathrm{O}$ acúmulo de $\mathrm{K}$ nas raízes das plantas produz um gradiente de pressão osmótico que atrai a água em direção as raízes. As plantas deficientes em K são menos capazes de absorver água e estão mais sujeitas ao estresse quando o teor de água está abaixo do crítico para cultura (NELSON, 2005). Da mesma maneira, o aumento da umidade do solo favorece a difusão do $\mathrm{K}$, aumentando a disponibilidade deste elemento para as plantas (OLIVEIRA et al., 2004).

A necessidade de água na cultura da soja vai aumentando com o desenvolvimento da planta, atingindo o máximo durante a floração-enchimento de grãos, decrescendo após esse período. Neste período em que a demanda é máxima, a ocorrência de défice hídrico provoca alterações fisiológicas nas plantas, causando a queda prematura de folhas, de flores e abortamento de vagens, resultando em menor rendimento de grãos (NELSON, 2005).

A cultura da soja, normalmente, responde a adubações potássicas, principalmente em solos de clima tropical (FOLONI; ROSOLEM, 2008). Entre as práticas culturais que visam aumentar a eficiência de uso da água pelas culturas, o fornecimento adequado de nutrientes tem um papel relevante, em especial o K pelas funções que desempenha no metabolismo vegetal (NELSON, 2005). Isto destaca a importância dos programas de adubação potássica nesta cultura (OLIVEIRA et al., 2001).

Na região de Dourados, $\mathrm{MS}$, a precipitação acumulada durante o ciclo de uma lavoura de soja semeada dentro da época recomendada, normalmente, supera $750 \mathrm{~mm}$, suficiente para atender a demanda total da cultura em um ciclo (FARIAS et al., 2001). No entanto, a distribuição irregular das chuvas, ocasiona períodos de veranicos e/ou estiagens, que é a principal causa de perdas agrícolas na região (FIETZ et al., 2002).

Objetivou-se com este trabalho avaliar o efeito de diferentes doses de $\mathrm{K}$ e níveis de umidade do solo sobre os componentes da produção da soja em Latossolo Vermelho Distroférrico, em casa de vegetação.

\section{Material e métodos}

O experimento foi realizado em casa de vegetação, na Faculdade de Ciências Agrárias da Universidade Federal da Grande Dourados (UFGD), em Dourados, MS, no ano agrícola de 2006/2007, em vasos contendo $5 \mathrm{dm}^{3}$ de solo seco ao ar, passados em peneira de $4 \mathrm{~mm}$ de malha. O solo utilizado foi um Latossolo Vermelho Distroférrico, textura argilosa, coletado na camada de 0 a $30 \mathrm{~cm}$ de profundidade, em uma área sob Brachiaria decumbens Stapf., sem pastejo e apresentava os seguintes atributos químicos e físicos: $\mathrm{pH}$ em água $=4,9 ; \mathrm{P}_{\text {Mehlich } 1}=3 \mathrm{mg} \mathrm{dm}{ }^{-3} ; \mathrm{K}_{\text {Mehlich } 1}^{+}=0,12 \mathrm{cmol}_{\mathrm{c}} \mathrm{dm}^{-3}$; $\mathrm{Ca}^{2+}, \mathrm{Mg}^{2+}, \mathrm{H}^{+}+\mathrm{Al}^{3+}, \mathrm{SB}, \mathrm{T}\left(\mathrm{cmol} \mathrm{dm}^{-3}\right)=1,36 ; 0,40 ; 9,90$; 1,$88 ; 11,78$ respectivamente; $\mathrm{V} \%=15$; argila $=680 \mathrm{~g} \mathrm{~kg}^{-1}$; silte $=130 \mathrm{~g} \mathrm{~kg}^{-1} ;$ areia $=190 \mathrm{~g} \mathrm{~kg}^{-1}$.

$\mathrm{O}$ delineamento experimental empregado foi $\mathrm{o}$ de blocos casualizados, com os tratamentos arranjados em esquema fatorial $5 \times 3$, sendo cinco doses de $\mathrm{K}$ e três faixas de umidade, com cinco repetições. As doses de $\mathrm{K}$ foram de 0;30;60;120 e $180 \mathrm{mg} \mathrm{dm}^{-3}$, utilizando como fonte o cloreto de potássio, aplicado ao solo antes da semeadura da soja via solução, e as faixas de umidade do solo (U) de 35 a 40; 47,5 a 52,5; e 60 a $65 \%$ do volume total de poros (VTP), representadas por $\mathrm{U}_{1}, \mathrm{U}_{2}$ e $\mathrm{U}_{3}$, respectivamente. $\mathrm{O}$ solo foi mantido com umidade correspondente a $95 \%$ da capacidade de campo, para todos os tratamentos, até o início do período reprodutivo da soja, estádio R1 (FEHR; CAVINESS, 1977). A partir deste período foram mantidas as faixas de umidade $U_{1}, U_{2}$ e $\mathrm{U}_{3}$. Para o controle da umidade foi calculada a massa total de cada vaso com planta no limite superior da faixa de umidade, adotado como massa de referência. Duas vezes ao dia os vasos tiveram sua massa aferida em balança com precisão de 0,1 g e sempre que necessário adicionava água, até atingir a massa de referência.

Utilizou-se calcário dolomitico "filler" (PRNT 100\%) na correção da acidez do solo, visando elevar a saturação por bases para 70\%. Após um período de 15 dias da incubação, efetuou-se a adubação com macro e micronutrientes segundo recomendação para o cultivo em casa de vegetação descrita por Novais et al. (1991). O nitrogênio aplicado na semeadura 
foi apenas $25 \%$ da recomendação, tendo em vista a inoculação com bactérias do gênero Bradyrhizobium, recomendadas para soja, na concentração de $150 \mathrm{~mL}$ do inoculante para $50 \mathrm{~kg}$ de sementes.

A semeadura de seis sementes foi realizada no dia 14 de dezembro de 2006, cuja cultivar foi a M-SOY 5942, de ciclo precoce. No $14^{\circ}$ dia após a semeadura realizou-se o desbaste, deixando-se duas plântulas por vaso.

Após as plantas atingirem a maturação fisiológica e secarem naturalmente, efetuou-se a colheita. As características avaliadas foram: rendimento de grãos (RG), peso de cem grãos (PG), número de grãos por vaso (TG), teor de potássio no grão (TK) e número de vagens viáveis (NV). Os grãos colhidos foram acondicionados em sacos de papel e mantidos em estufa com circulação forçada de ar, a $60^{\circ} \mathrm{C}$, até massa constante, a fim de uniformizar o teor de água e, em seguida, determinouse o rendimento de grãos e a massa de cem grãos. Os grãos foram triturados e, realizou-se a digestão nítricoperclórica das amostras, determinando-se nos extratos os teores de $\mathrm{K}$ por fotometria de chama (MALAVOLTA et al., 1997). Foram consideradas viáveis as vagens que apresentavam pelo menos um grão formado.

Os dados foram submetidos à análise de variância, sendo o procedimento de ajustamento de curvas de respostas as doses de $\mathrm{K}$ e níveis de umidade do solo realizado através do software $\mathrm{R}$ (R FOUNDATION FOR STATISTICAL COMPUTING, 2010). Os termos não significativos foram removidos do modelo até que se chegasse a um modelo adequado para a predição. Para a variável número de vagens viáveis, ajustou-se um modelo linear generalizado em que se assumiu distribuição binomial para a proporção de vagens viáveis com função de ligação logit (DOBSON, 2002).

Para a obtenção dos modelos finais, partiu-se de um modelo quadrático completo, desconsiderando os termos de maior ordem não significativos. Os termos lineares dos modelos, quando na presença dos termos quadráticos, foram mantidos mesmo quando não apresentaram significância (BOX; DRAPER, 2007).

\section{Resultados e discussão}

A maturidade fisiológica das plantas (estádio R7) (FEHR; CAVINESS, 1977) aconteceu a partir dos 82 dias da semeadura, começando pelas plantas que compunham os tratamentos com as menores doses de $\mathrm{K}$, independente do nível de água. À medida que aumentaram as doses de K houve maior duração do ciclo, totalizando até 90 dias. $\mathrm{O}$ encurtamento do ciclo deve estar relacionado com a deficiência de K, contudo Oliveira et al. (2001) não observaram alteração do ciclo, em plantas deficientes de K.

Observou-se interação entre $\mathrm{K}$ e $\mathrm{U}$ apenas para as variáveis $\mathrm{RG}$ e TG (TAB. 1). $\mathrm{O} \mathrm{K}$ acarretou efeito linear e quadrático significativo para todas as variáveis, corroborando com Oliveira et al. (2001), diferente da U que não acarretou efeito linear para PG e TK e efeito quadrático para RG e TK.

O modelo final para TG teve todos os termos do modelo quadrático completo. Para PG e NV não incluiu o termo da interação U x K. Para RG desconsiderouse o termo quadrático para umidade, enquanto para TK considerou-se apenas os termos em função do K.

Tabela 1 - Resumo da análise de variância/deviance para as variáveis avaliadas: rendimento de grãos (RG), peso de cem grãos (PG), número total de grãos por vaso (TG), teor de potássio no grão (TK), número de vagens viáveis (NV)

\begin{tabular}{|c|c|c|c|c|c|c|c|c|c|c|c|}
\hline \multirow{2}{*}{$\mathrm{FV}$} & \multicolumn{8}{|c|}{ Quadrados médios } & \multicolumn{3}{|c|}{ Deviance $^{\S}$} \\
\hline & GL & $\mathrm{RG}$ & & PG & & TG & & TK & & NV & \\
\hline Bloco & 4 & 27,71 & $*$ & 2,090 & & 1554 & $*$ & 4,08 & & 5,58 & \\
\hline Umidade (U) & 1 & 420,85 & $* *$ & 0,952 & & 22092 & $* *$ & 5,08 & & 4,06 & $*$ \\
\hline Potássio (K) & 1 & 1951,54 & $* *$ & 103,598 & $* *$ & 45103 & $* *$ & 391,48 & $* *$ & 355,81 & $* *$ \\
\hline $\mathrm{U}^{2}$ & 1 & 4,29 & & 26,527 & $* *$ & 9017 & $* *$ & 0,41 & & 13,74 & $* *$ \\
\hline $\mathrm{K}^{2}$ & 1 & 493,51 & $* *$ & 20,819 & $* *$ & 13163 & $* *$ & 32,22 & $* *$ & 111,59 & $* *$ \\
\hline $\mathrm{U} \times \mathrm{K}$ & 1 & 173,13 & $* *$ & 0,024 & & 5488 & $* *$ & 2,69 & & 0,63 & \\
\hline Resíduo & 65 & 8,74 & & 2,206 & & 610 & & 3,61 & & 117,5 & \\
\hline $\mathrm{CV}(\%)$ & & 11,3 & & 10,1 & & 13,1 & & 10,4 & & - & \\
\hline
\end{tabular}

* e ** indicam significativo a $5 \%$ e $1 \%$ pelo teste $\mathrm{F}$, respectivamente; ${ }^{\S} \mathrm{Na}$ análise de deviance aplicou-se o teste Qui-quadrado 
Tabela 2 - Estimativas dos coeficientes do modelo final para cada variável resposta: rendimento de grãos (RG), peso de cem grãos (PG), número total de grãos por vaso (TG), teor de potássio no grão (TK), número de vagens viáveis (NV)

\begin{tabular}{lccccrcrrrr}
\hline \multicolumn{1}{c}{ Parâmetro } & $\mathrm{RG}$ & & $\mathrm{PG}$ & & $\mathrm{TG}$ & & $\mathrm{TK}$ & \multicolumn{1}{c}{$\mathrm{NV}^{\S}$} & \\
\hline Intercepto & 12,86000 & $* *$ & 31,530000 & $* *$ & $-255,60000$ & $* *$ & 14,230000 & $* *$ & 31,530000 & $* *$ \\
Umidade (U) & 0,052410 & & $-0,818500$ & $* *$ & 15,56000 & $* *$ & - & & $-0,818500$ & $* *$ \\
Potássio (K) & 0,108000 & $* *$ & 0,047820 & $* *$ & 0,47610 & & 0,072220 & $* *$ & 0,047820 & $* *$ \\
$\mathrm{U}^{2}$ & - & & 0,008074 & $* *$ & $-0,14890$ & $* *$ & - & & 0,008074 & $* *$ \\
$\mathrm{~K}^{2}$ & $-0,000792$ & $* *$ & $-0,000163$ & $* *$ & $-0,00409$ & $* *$ & $-0,000202$ & $* *$ & $-0,000163$ & $* *$ \\
$\mathrm{U}$ x K & 0,002304 & $* *$ & - & & 0,01297 & $* *$ & - & & - & \\
\hline
\end{tabular}

$* \mathrm{e}^{* *}$ indicam significativo a $5 \%$ e $1 \%$ pelo teste $\mathrm{t}$, respectivamente; ${ }^{\S}$ Aplicou-se o teste $\mathrm{z}$

Para doses de $\mathrm{K}$ fixadas entre 0 e $50 \mathrm{mg} \mathrm{dm}^{-3}$, não se observa variação do RG em função da umidade, dado o paralelismo das isolinhas com o eixo da umidade nesta região (FIG. 1), contudo observa-se incrementos de RG pelo aumento de $\mathrm{K}$, para todos os níveis de umidade do solo. O aumento de rendimento de grãos na soja em resposta à adubação potássica, é relatada por diversos autores, como Nelson et al. (2005) e Foloni; Rosolen (2008) para lavouras em sistemas de cultivo convencional e direto, respectivamente.

Com as doses de $\mathrm{K}$ superiores a $100 \mathrm{mg} \mathrm{dm}^{-3}$ observou-se uma tendência de paralelismo das isolinhas em ralação ao eixo do K e um grande incremento para RG em função do aumento da umidade. Nas menores doses, o K é o fator limitante independente da umidade do solo. Já para as maiores doses observa-se efeito inverso, onde o fator limitante é a umidade do solo, independente do K (FIG. 1). A região de máximo $\mathrm{RG}$, dentro da amplitude dos níveis de $\mathrm{K}$ e umidade estudados, ficou situada para doses de $150 \mathrm{mg} \mathrm{dm}^{-3}$ e umidade de $60 \%$.

Para a menor umidade estudada, observa-se incremento de RG em função de doses de K (FIG. 1). Para a maior umidade deste estudo (60\%), o RG máximo $35,1 \mathrm{~g}$ foi conferido pela dose de $\mathrm{K}$ de $150 \mathrm{mg} \mathrm{dm}^{-3}$. A dose de $\mathrm{K}$ de $125 \mathrm{mg} \mathrm{dm}^{-3}$ conferiu o valor máximo predito de RG, 27,6 g, para a umidade de $40 \%$, o que corresponde a $78 \%$ do RG máximo, dentro do intervalo estudado. A observação de incremento de RG na menor umidade com o aumento das doses de $\mathrm{K}$ e o RG na menor umidade ter atingido $78 \%$ do RG máximo, indica uma compensação do déficit hídrico com o aumento do K disponível para as plantas, além de proporcionar plantas vigorosas, capazes de manter o RG mesmo sob condições de déficit hídrico, dentro dos limites deste estudo. O papel do K na condutância estomática, aumenta a eficiência do uso da água pela planta, o que implica em menor quantidade de água utilizada por unidade de matéria seca acumulada (PETTIGREW, 2008), em adição, a boa nutrição em $\mathrm{K}$ garante a atividade da ATPase, essencial para transformação da energia luminosa em energia química pela fotossíntese (PETTIGREW, 2008), essencial para um bom RG.

Para as doses de $\mathrm{K}$ fixadas entre 0 e $100 \mathrm{mg} \mathrm{dm}^{-3}$, observa-se pequena variação do PG em função da umidade, dado o paralelismo das isolinhas com eixo da umidade nesta região (FIG. 2), contudo observa-se incrementos de PG pelo aumento de $\mathrm{K}$, para todos os níveis de umidade do solo. A partir da dose $100 \mathrm{mg} \mathrm{dm}^{-3}$ de $\mathrm{K}$, observa-se uma diminuição da taxa de incremento em função do $\mathrm{K}$, descrita pela tendência de paralelismo das isolinhas com o eixo do K. A presença de um ponto de sela na Figura 2, para teores de $\mathrm{K}$ acima de $100 \mathrm{mg} \mathrm{dm}^{-3}$, compromete a interpretação do efeito da umidade. $\mathrm{O}$ ponto de sela é indicativo da presença de uma região de estacionaridade, onde a PG tem variação desprezível em função do efeito dos fatores.

Figura 1 - Valor predito para rendimento de grãos (RG) em função da dose de potássio e umidade

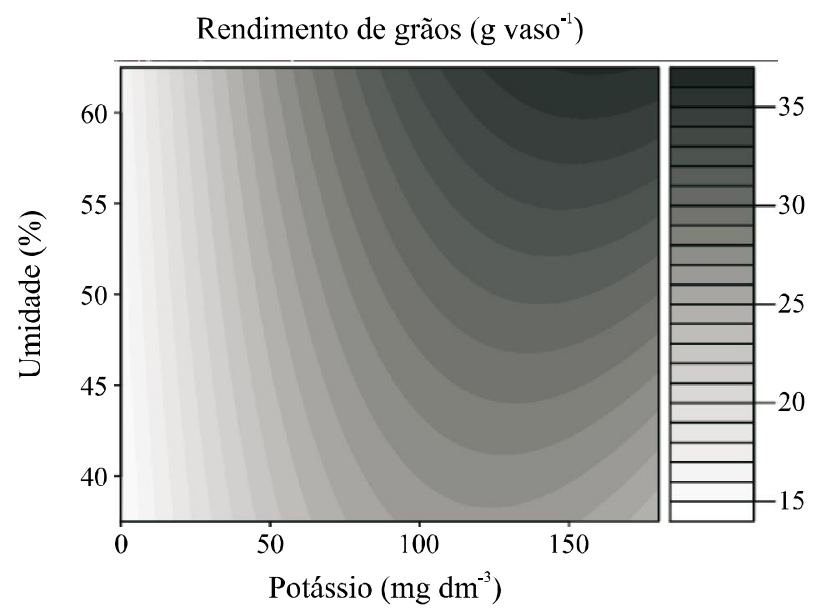


Pode-se observar que a umidade e o K são fatores limitantes doTG, pois, dado que um dos fatores esteja no nível mínimo, a variação do outro fator não resulta em incremento de TG (FIG. 3). À medida que se aumenta simultaneamente os níveis dos fatores, observa-se um aumento pronunciado do TG, em que o ponto de máxima é conferido pela umidade de $59 \%$ e dose de $\mathrm{K}$ de $151 \mathrm{mg} \mathrm{dm}^{-3}$, com valor predito de 230 grãos por vaso. Assim, sob condições normais de umidade o $\mathrm{K}$ é um fator indispensável para garantir elevado número de grãos na cultura da soja.

Para os teores de $\mathrm{K}$ no grão foi observado apenas efeito das doses de K (FIG. 4). O incremento dos teores de $\mathrm{K}$ no grão tem uma relação quadrática com as doses de $\mathrm{K}$, apresentando o máximo acúmulo de $\mathrm{K}$ no grão, 20,6 g kg-1,

Figura 2 - Valor predito para massa de 100 grãos (PG) em função da dose de $\mathrm{K}$ e umidade

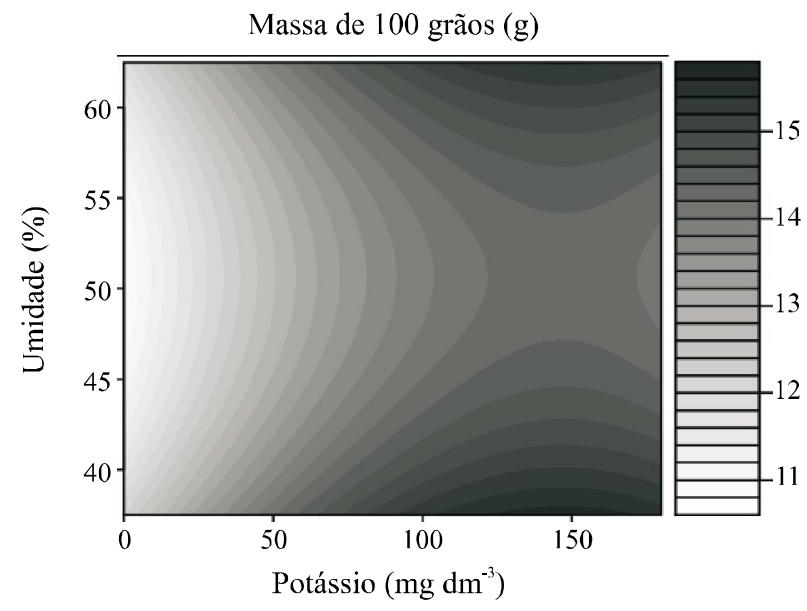

Figura 3 - Valor predito para o total de grão por vaso (TG) em função das doses de $\mathrm{K}$ e umidade

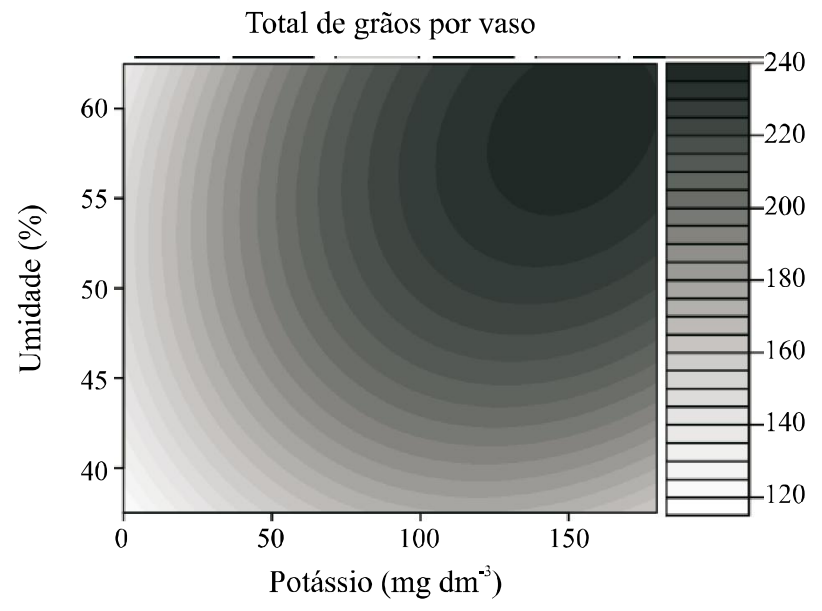

Figura 4 - Valor predito para potássio no grão (TK) em função da dose de potássio

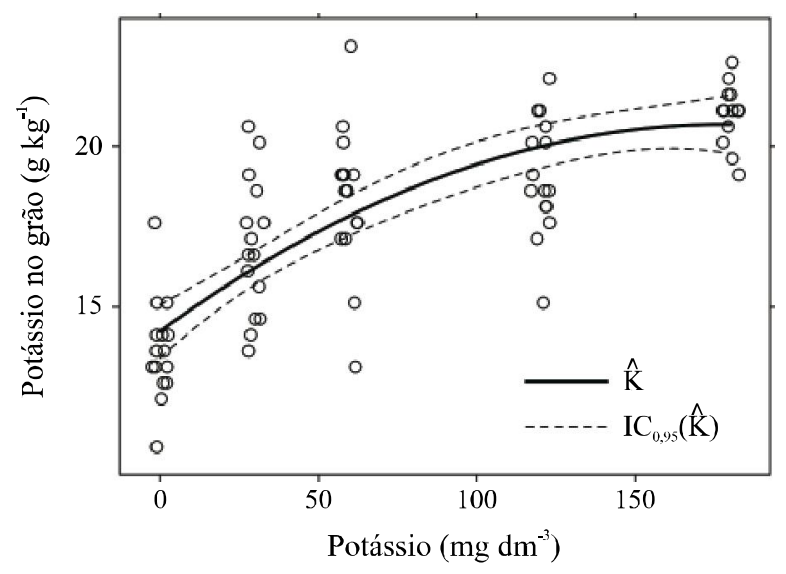

Figura 5 - Valor predito porcentagem de vagens viáveis (NV) em função das doses de $\mathrm{K}$ e umidade

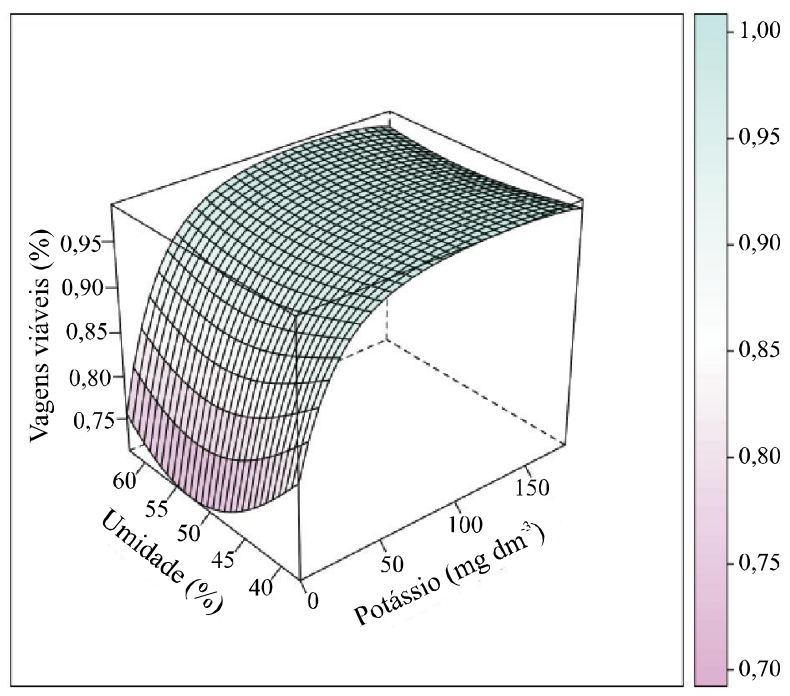

na dose de $178 \mathrm{mg} \mathrm{dm}^{-3}$. $\mathrm{O}$ transporte de fotoassimilados pelo floema demanda a presença de $\mathrm{K}$, sendo restrito quando este nutriente está deficiente (GURGEL et al., 2010), assim, o aumento de K no grão é esperado, por se tratar do principal dreno da planta de soja.

Para o NV observa-se que umidade teve efeito significativo, porém pouco pronunciado na comparação com o efeito da dose de K (FIG. 5). Observa-se que até aproximadamente $50 \mathrm{mg} \mathrm{de} \mathrm{K} \mathrm{dm}^{-3}$ tem-se uma elevada taxa de incremento do NV, indicando uma forte dependência dos níveis de $\mathrm{K}$ no solo para a formação de grão na vagem. A partir da dose de $50 \mathrm{mg} \mathrm{dm}^{-3}$ já se observa uma estacionaridade da taxa de incremento no NV. Para a dose zero de K, o ligeiro aumento do NV nos 
dois extremos de umidade, provavelmente refere-se a vagens com apenas um grão, o que pode ser observado na Figura 3, onde os extremos de umidade na dose zero de $\mathrm{K}$, apresenta menor TG.

\section{Conclusões}

1.Para a variável rendimento de grãos, o $\mathrm{K}$ e a umidade tiveram efeito compensatório entre si, onde um fator tende a reduzir o efeito da deficiência do outro fator;

2. A soja teve resposta positiva à adubação potássica, aumentando seu rendimento de grãos, massa de 100 semente, teor de K no grão e número de vagens viáveis;

3. O K reduziu os efeitos do deficit hídrico na soja.

\section{Referências}

BOX, G. E. P.; DRAPER,. N. R.. Response surfaces, mixtures, and ridge analyses. 2. ed. Wiley-Interscience, 2007. 857 p.

DOBSON, A. D. An introduction to generalized linear models. 2. ed. Boca Raton: Chapman \& Hall/CRC, 2002. 221 p.

FEHR, W. R.; CAVINESS, C. E. Stages of soybean development. Ames: Iowa State University, 1977. 12 p.

FARIAS, J. R. B., et al. Caracterização do risco de déficit hídrico nas regiões produtoras de soja no Brasil. Revista Brasileira de Agrometeorologia, v. 9, n. 3, p. 415-421, 2001.

FIETZ, C. R.; URCHEI, M. A. Deficiência hídrica na cultura da soja na região de Dourados, MS. Revista Brasileira de Engenharia Agrícola e Ambiental, v. 06, n. 02, p. 262-265, 2002.

FOLONI, J. S. S.; ROSOLEM, C. A. Produtividade e acúmulo de potássio na soja em função da antecipação da adubação potássica no sistema plantio direto. Revista Brasileira de Ciência do Solo, v. 32, p. 1549-1561, 2008.

GURGEL, M. T.; GHEYI, H. R.; OLIVEIRA, F. H. T. Acúmulo de matéria seca e nutrientes em meloeiro produzido sob estresse salino e doses de potássio. Revista Ciência Agronômica, v. 41, n. 01, p. 18-28, 2010.

LOPES, A. S. Reserva de minerais potássicos e produção de fertilizantes potássicos no Brasil. In: YAMADA, T.;ROBERTS, T. L. (Ed.). Potássio na agricultura brasileira. Piracicaba: Potafos, 2005. p. 21-32.

MALAVOLTA, E.; VITTI, G. C.; OLIVEIRA, S. A. de. Avaliação do estado nutricional das plantas: princípios e aplicações. 2. ed. Piracicaba: POTAFOS, 1997. 319 p.

MELO, V. F. et al. Potássio e magnésio em minerais das frações areia e silte de diferentes solos. Revista Brasileira de Ciência do Solo, v. 24, p. 269-284, 2000.

NELSON, K. A.; MOTAVALLI, P. P.; NATHAN, M. Response of No-Till Soybean [ (L.) Merr.] to Timing of Preplant and Foliar Potassium Applications in a Claypan Soil. Agronomy Journal, v. 97, n. 03, p. 832-838, 2005.

NOVAIS, R. F.; NEVES, J. C. L.; BARROS, N. F. Ensaio em ambiente controlado. In: OLIVEIRA, A. J. et al. (Coord.). Métodos de pesquisa em fertilidade do solo. Brasília, DF: EMBRAPA SEA, 1991. p. 189-253. (EMBRAPA-SEA. Documentos, 3).

OLIVEIRA, F. A.; CARMELLO, Q. A. C.; MASCARENHAS, H. A. A. Disponibilidade de potássio e suas relações com cálcio e magnésio em soja cultivada em casa-de-vegetação. Scientia Agricola, v. 58, n. 02, p. 329-335, 2001.

OLIVEIRA, R. H.; ROSOLEM, C. A.; TRIGUEIRO, R. M. Importância do fluxo de massa e difusão no suprimento de potássio ao algodoeiro como variável de água e potássio no solo. Revista Brasileira de Ciência do Solo, v. 28, n. 03, p. 439-445, 2004.

PETTIGREW, W. T. Potassium influences on yield and quality production for maize, wheat, soybean and cotton. Physiologia Plantarum. v. 133, p. 670-681, 2008.

R FOUNDATION FOR STATISTICAL COMPUTING. R: A language and environment for statistical computing. 2010. Disponívelem: <http://softlibre.unizar.es/manuales/aplicaciones/ r/fullrefman.pdf >. Acesso em: 10 abr. 2010.

SILVA, V. A. et al. Kinetics of K release from soils of Brazilian coffee regions: effect of organic acids. Revista Brasileira de Ciência do Solo, v. 32, n. 02, p. 533-540, 2008. 